\title{
Fabrication of Supramolecular n/p-Nanowires via Coassembly of Oppositely Charged Peptide-Chromophore Systems in Aqueous Media
}

Mohammad Aref Khalily, ${ }^{\dagger}$ Gokhan Bakan, ${ }^{\dagger, \dagger}$ Betul Kucukoz, ${ }^{\S, \|}$ Ahmet Emin Topal, ${ }^{\dagger}$ Ahmet Karatay, ${ }^{\S}$ H. Gul Yaglioglu, ${ }^{\S}$ Aykutlu Dana, ${ }^{\dagger}$ and Mustafa O. Guler ${ }^{* \dagger,} \perp^{+}$

${ }^{\dagger}$ Institute of Materials Science and Nanotechnology and National Nanotechnology Research Center (UNAM), Bilkent University, Ankara 06800, Turkey

${ }^{\ddagger}$ Department of Electrical and Electronics Engineering, Atilim University, Ankara 06836, Turkey

${ }^{\S}$ Department of Physics Engineering, Ankara University, Ankara 06100, Turkey

"Department of Chemistry and Chemical Engineering, Chalmers University of Technology, 41296 Gothenburg, Sweden

${ }^{\perp}$ Institute for Molecular Engineering, University of Chicago, Chicago, Illinois 60637, United States

Supporting Information
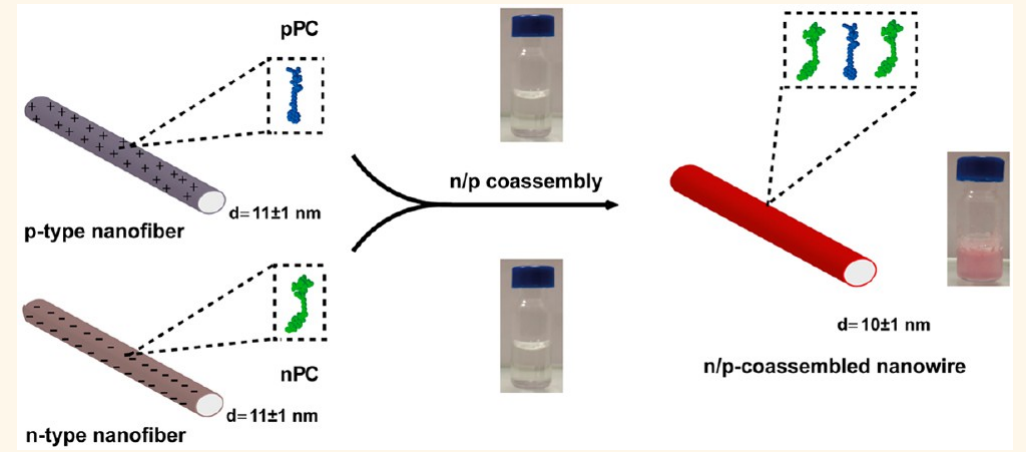

n/p-coassembled nanowire

ABSTRACT: Fabrication of supramolecular electroactive materials at the nanoscale with well-defined size, shape, composition, and organization in aqueous medium is a current challenge. Herein we report construction of supramolecular charge-transfer complex one-dimensional (1D) nanowires consisting of highly ordered mixed-stack $\pi$-electron donoracceptor (D-A) domains. We synthesized n-type and p-type $\beta$-sheet forming short peptide-chromophore conjugates, which assemble separately into well-ordered nanofibers in aqueous media. These complementary p-type and n-type nanofibers coassemble via hydrogen bonding, charge-transfer complex, and electrostatic interactions to generate highly uniform supramolecular $\mathbf{n} / \mathbf{p}$-coassembled $1 \mathrm{D}$ nanowires. This molecular design ensures highly ordered arrangement of $\mathrm{D}-\mathrm{A}$ stacks within $\mathbf{n}$ /p-coassembled supramolecular nanowires. The supramolecular $\mathbf{n} / \mathbf{p}$-coassembled nanowires were found to be formed by $\mathrm{A}-\mathrm{D}-\mathrm{A}$ unit cells having an association constant $\left(K_{\mathrm{A}}\right)$ of $5.18 \times 10^{5} \mathrm{M}^{-1}$. In addition, electrical measurements revealed that supramolecular $n / p$-coassembled nanowires are approximately 2400 and 10 times more conductive than individual n-type and p-type nanofibers, respectively. This facile strategy allows fabrication of well-defined supramolecular electroactive nanomaterials in aqueous media, which can find a variety of applications in optoelectronics, photovoltaics, organic chromophore arrays, and bioelectronics.

KEYWORDS: nanowires, self-assembly, coassembly, supramolecular, peptide chromophore, conductivity

upramolecular electronics is an emerging research field,
which exploits noncovalent interactions to assemble $\pi$ -
conjugated molecular elements into well-defined nano-
materials with semiconductor properties such as light emission,
light harvesting, and charge carrier transport for optoelectronic,
photovoltaic, bioelectronics, and tissue engineering applica-

Received: March 23, 2017

Accepted: July 5, 2017

Published: July 5, 2017 
Scheme 1. Chemical Structures of (a) p-Type PC (pPC) and (b) n-Type PC (nPC) Molecules and (c) Coassembly of p- and nType Nanofibers into Supramolecular $\mathrm{n} / \mathrm{p}$-Coassembled Nanowire
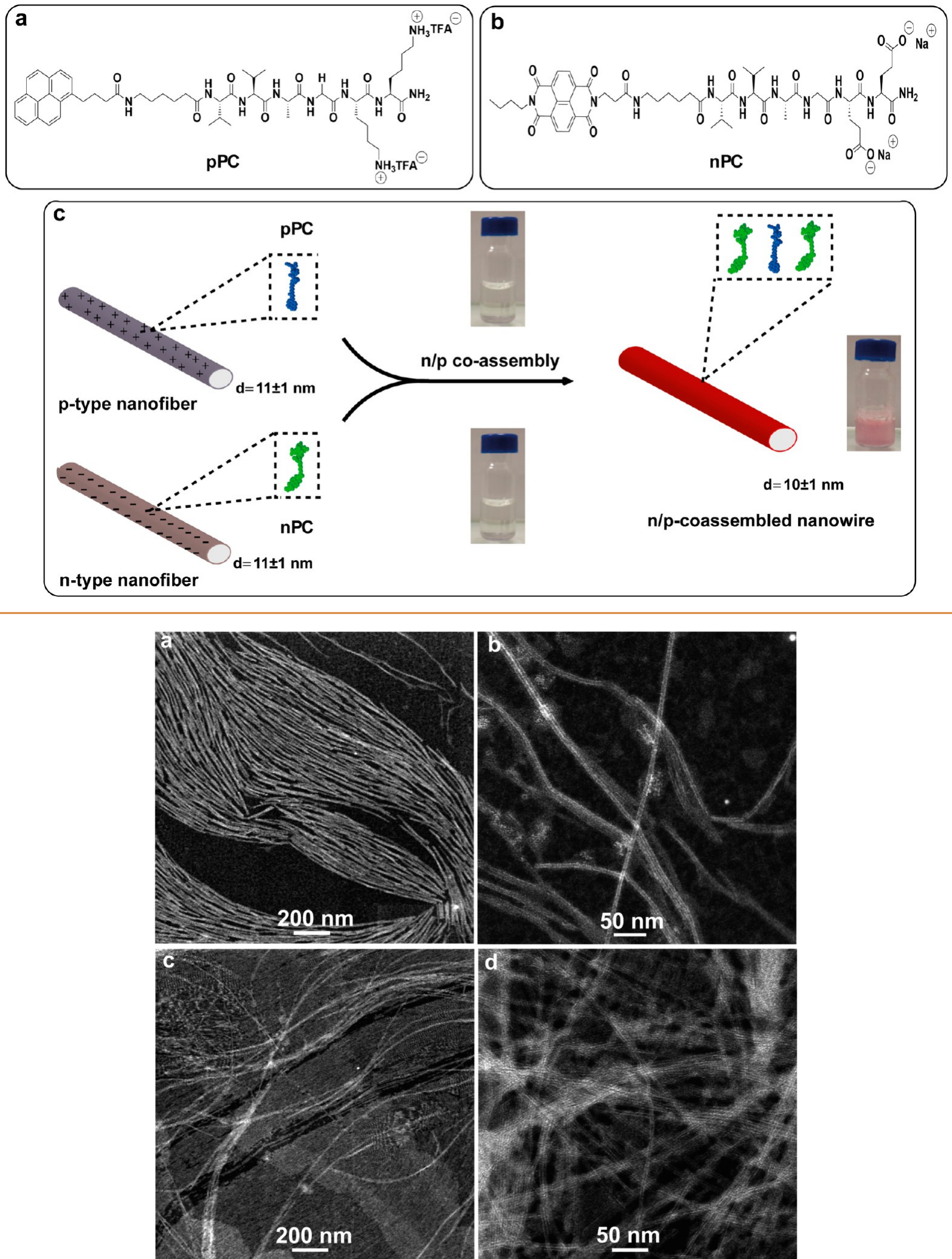

Figure 1. STEM images of pPC ( $a$ and $b)$ and $\mathrm{nPC}(\mathrm{c}$ and $\mathrm{d})$ nanofibers with diameter of $11 \pm 1 \mathrm{~nm}$.

tions. ${ }^{1-4}$ Efficiency of charge transport, energy migration, and mobility of charge carriers in these supramolecular onedimensional (1D) nanowires is directly dependent on supra- molecular order of $\pi$-conjugated chromophores. ${ }^{4,5}$ Therefore, achieving efficient cofacial $\pi-\pi$ interactions among hydrophobic semiconducting chromophores in aqueous medium is a 
a
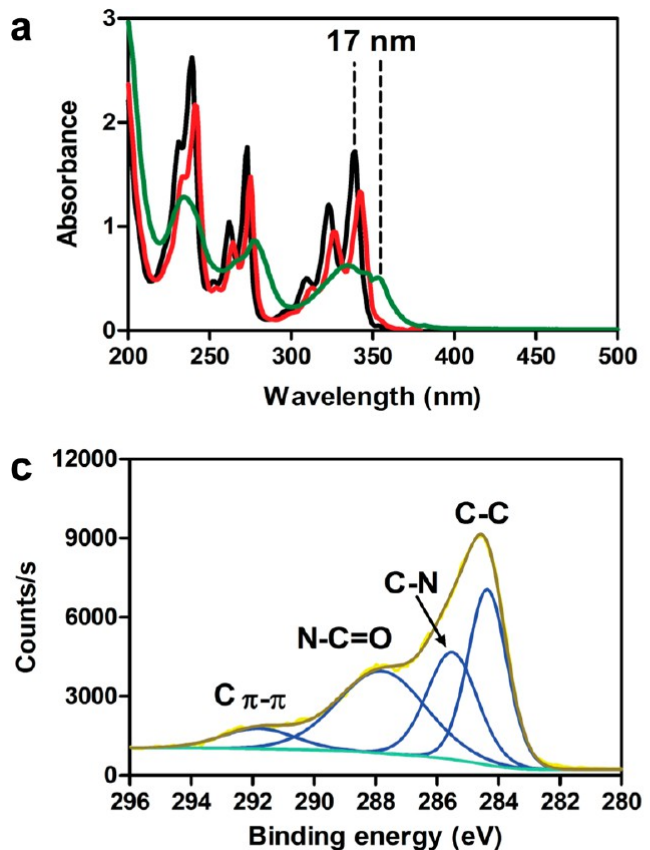
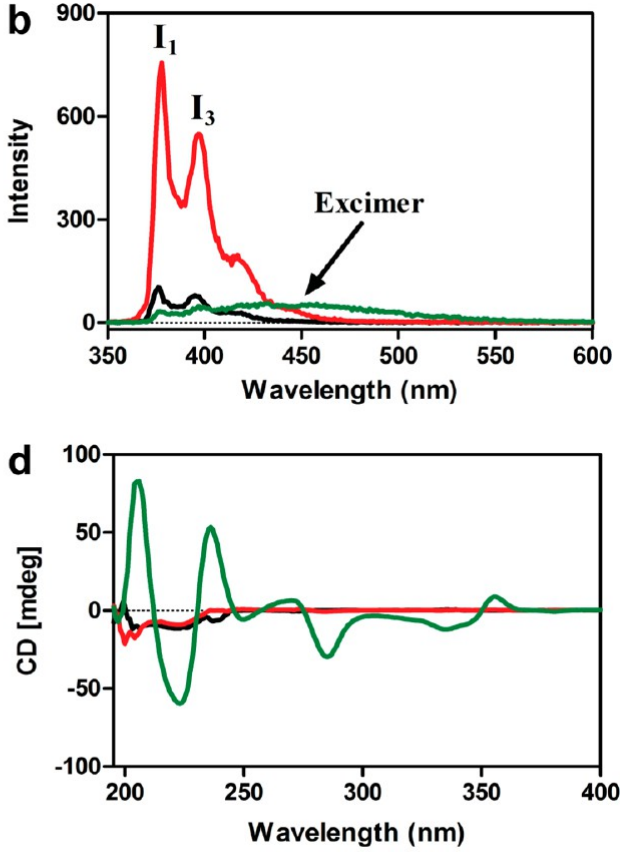

- pPC-TFE - pPC- $\mathrm{H}_{2} \mathrm{O}-\mathrm{pPC}-\mathrm{pH} 10$

Figure 2. Spectroscopic characterization of pPC assembly. (a) UV-vis absorption and (b) fluorescence emission spectra (excitation wavelength $=340 \mathrm{~nm}$ ) of pPC. (c) XPS analysis (Gaussian deconvolution of the C 1s signal) of assembled pPC powder and (d) CD spectra of pPC molecules.

highly desired goal in the area of supramolecular electronics. A promising strategy to fabricate $1 \mathrm{D}$ electroactive nanomaterials with maximum cofacial $\pi-\pi$ interactions in aqueous media is to conjugate $\mathrm{n}$-type or $\mathrm{p}$-type semiconducting molecules to selfassembling short peptide sequences. ${ }^{2,6}$ Particularly, conjugation to $\beta$-sheet forming peptides not only ensures solubility of hydrophobic semiconducting building blocks in aqueous media but also allows directing long-range spatial organization of semiconducting chromophores. ${ }^{7,8}$ The n-type and p-type semiconducting supramolecular nanowires usually suffer from low conductivities. ${ }^{9-11}$ To address this problem, p-type and ntype semiconducting $1 \mathrm{D}$ nanowires are doped either by an oxidizing (iodine) $)^{11}$ or reducing agents (hydrazine), ${ }^{10}$ respectively. Another strategy is to assemble suitable $\pi$-electron donor (D) with an $\pi$-electron acceptor (A) in alternating manner to form charge-transfer complexes (CTC) with improved (photo) conductivities. ${ }^{11-13}$ Lopez-Andarias et al. demonstrated that fabricated CTC made up of alternately segregated D-A nanodomains exhibited tremendous photoconductivity of $0.8 \mathrm{~cm}^{2} \mathrm{~V}^{-1} \mathrm{~s}^{-1}$. ${ }^{12}$ Similarly, Nalluri et al. constructed CTC xerogels composed of D-A domains enhancing the conductivity up to $10^{6}$-fold. ${ }^{11}$ Despite promising efforts, there are only few reports which illustrate fabrication of well-defined supramolecular $\mathrm{n} / \mathrm{p}$-nanowires in aqueous medium. $^{12,14,15}$

Here we report fabrication of well-defined supramolecular $n$ / $\mathrm{p}$-coassembled nanowires in aqueous media. We designed and synthesized $\beta$-sheet forming p-type peptide-chromophore (pPC) (Scheme 1a) and n-type peptide-chromophore (nPC) (Scheme $1 \mathrm{~b}$ ) conjugates. Positively charged PPC and negatively charged nPC molecules individually assemble into highly uniform p-type and n-type nanofibers, respectively, with diameter of $11 \pm 1 \mathrm{~nm}$ and microns in length as imaged by scanning transmission electron microscope (STEM) (Figure 1). These complementary p-type and n-type nanofibers coassemble via hydrogen bonding, CTC, and electrostatic interactions to generate well-ordered supramolecular $\mathrm{n} / \mathrm{p}$ coassembled 1D nanowires (Scheme 1c). This smart molecular design ensures highly ordered arrangement of D-A stacks within $\mathrm{n} / \mathrm{p}$-coassembled $\mathrm{ID}$ nanowires. Our findings demonstrate that supramolecular $\mathrm{n} / \mathrm{p}$-coassembled $1 \mathrm{D}$ nanowire is formed from $\mathrm{A}-\mathrm{D}-\mathrm{A}$ unit cells having a strong $K_{\mathrm{A}}$ of $5.18 \times$ $10^{5} \mathrm{M}^{-1}$. These supramolecular $\mathrm{n} / \mathrm{p}$-coassembled nanowires exhibit 2400- and 10-fold enhanced conductivity than the individual n-type and p-type nanofibers, respectively.

\section{RESULTS/DISCUSSION}

In this study, pyrene ( $\pi$-basic with molecular quadrupole moment $\mathrm{Qzz}=-13.8 \mathrm{~B}$ ) was conjugated to a $\beta$-sheet forming hexapeptide sequence $\left(\mathrm{H}_{2} \mathrm{~N} \text {-Ahx-VVAGKK-Am }\right)^{16}$ as $\pi$-electron donor (D) by using a solid-phase peptide synthesis (SPPS) method to synthesize pPC molecule (Figures S1-3). In this molecular design, VVA residues promote $\beta$-sheet formation, and KK residues not only ensure solubility of hydrophobic pyrene molecules in aqueous media but also provide positive charge (Figure S1). A six-carbon linker (Ahx) was introduced between pyrene chromophore and hexapeptide to provide flexibility among chromophores and allow them to arrange favorable orientation during self-assembly process. Aggregation of pPC molecule was studied by UV-vis, fluorescence, circular dichroism (CD), and X-ray photoelectron spectroscopies (XPS). Absorption of $\mathrm{pPC}$ molecules in trifluoroethanol (pPC-TFE) and in water $\left(\mathrm{pPC}-\mathrm{H}_{2} \mathrm{O}\right)$ showed well-resolved vibronic structures ranging from 250 to $350 \mathrm{~nm}$, which is characteristic for monomer pyrene chromophores (Figure 2a). ${ }^{17} \mathrm{~A}$ minor red shift in pyrene maxima was observed going from TFE (pPC-TFE) to $\mathrm{H}_{2} \mathrm{O}\left(\mathrm{pPC}-\mathrm{H}_{2} \mathrm{O}\right)$, which can be attributed to both solvent polarity difference and partial aggregation of pPC molecules in water. Upon complete charge neutralization by increasing the $\mathrm{pH}$ to 10 ( $\mathrm{pPC}-\mathrm{pH} 10)$, 

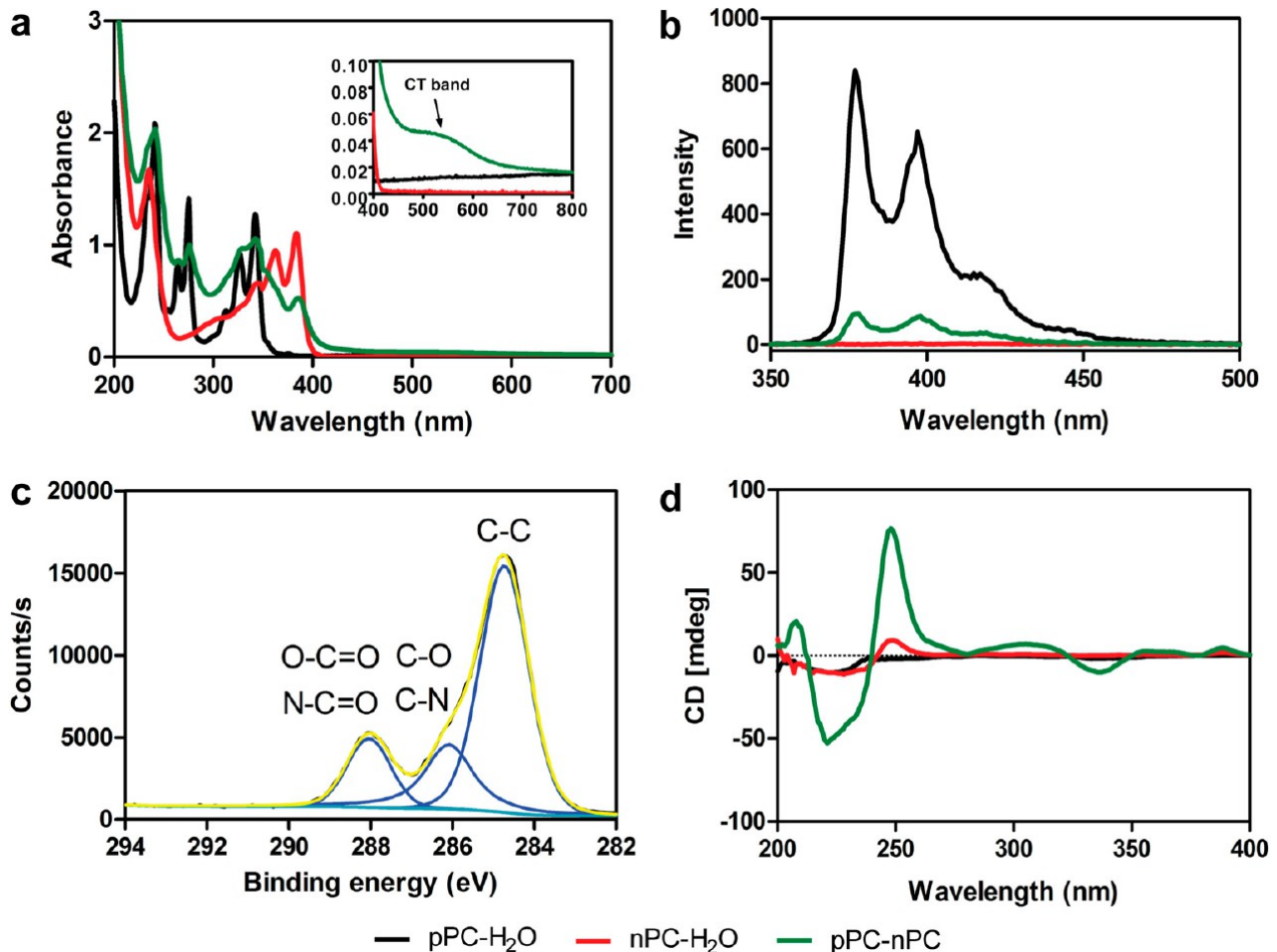

Figure 3. Spectroscopic characterization of pPC and nPC coassembly. (a) UV-vis absorption spectra and inset shows appearance of CT band. (b) Fluorescence emission spectra (excitation wavelength $=340 \mathrm{~nm}$ ) of pPC-nPC CT complex. (c) XPS analysis (Gaussian deconvolution of the C 1s signal) of PPC-nPC powder and (d) CD spectra of PPC and nPC coassembly in aqueous media.

the pPC molecules demonstrated a $17 \mathrm{~nm}$ red-shift followed by a decrease in intensity and broadening of absorption bands. These drastic changes in absorption bands revealed $J$-type $\pi-\pi$ interactions among pyrene molecules within p-type nanofibers. ${ }^{17}$ The emission profile of $\mathrm{pPC}$ in water $\left(\mathrm{pPC}-\mathrm{H}_{2} \mathrm{O}\right)$ showed vibronic structures which is caused by pyrene monomers (Figure $2 \mathrm{~b}$ ). The ratio of emission vibronic peaks $\mathrm{I}_{3}(375 \mathrm{~nm})$ and $\mathrm{I}_{1}(395 \mathrm{~nm})$ is extremely sensitive to polarity of the solvent and is widely used to probe the vicinity of highly hydrophobic pyrene chromophores. ${ }^{18}$ Electrostatic repulsions caused by protonated amine $\left(-\mathrm{NH}_{3}{ }^{+}\right)$groups of lysine residues prevent complete aggregation, thus pyrene molecules are exposed to relatively hydrophilic environment as the value of vibronic peaks $\left(\mathrm{I}_{3} / \mathrm{I}_{1}\right)$ is less than unity $\left(\mathrm{pPC}-\mathrm{H}_{2} \mathrm{O}\right)$. Upon charge neutralization by increasing the $\mathrm{pH}$ to 10 (pPC-pH 10), a drastic quenching in emission intensity of $\mathrm{pPC}$ followed by appearance of a new broad emission (440-550 nm) peak, which corresponds to pyrene excimers (Figure 2b). ${ }^{18}$ Planar luminophoric molecules such as perylene and pyrene can experience aggregation-caused quenching (ACQ) at high concentrations. ${ }^{19}$ During aggregation of pPC molecules in basic media ( $\mathrm{pPC}-\mathrm{pH} 10$ ), local concentration of pyrene molecules within pPC nanofibers increases and experiences strong $\pi-\pi$ stacking interactions, as we observed in XPS spectrum (Figure $2 \mathrm{c}$ ). Strong $\pi-\pi$ stacking interactions among pyrene moieties cause formation of species like excimers (Figure 2b), hence leading to the observed ACQ effect.

Self-assembly of pPC molecules triggered by charge neutralization does not only allow $\pi-\pi$ stacking of pyrene molecules but also allows them to closely position in a relatively hydrophobic environment (core of p-type nanofibers) as the ratio of vibronic peaks $\left(\mathrm{I}_{3} / \mathrm{I}_{1}\right)$ exceeds unity (Figure $2 \mathrm{~b}$ ). Lyophilized pPC-pH 10 powder analyzed by XPS exhibited a peak at $292 \mathrm{eV}$ (Figure 2c), which further confirmed the presence of $\pi-\pi$ stacking among closely spaced and spatially constrained pyrene molecules within pPC nanofibers. ${ }^{20}$

To investigate the long-range spatial organization of pyrene molecules within the p-type nanofibers, we further conducted $\mathrm{CD}$ analysis (Figure 2d). At basic conditions (pPC-pH 10), the pPC showed a strong bisignate signal with a negative Cotton effect between 200 and $230 \mathrm{~nm}$, which is attributed to formation of $\beta$-sheet secondary structures. ${ }^{21}$ In addition, weak CD signals were observed between 250 and $360 \mathrm{~nm}$, which confirms induction of chirality to pyrene chromophores via pPC self-assembly. On the other hand, partial aggregation of pPC molecules in water $\left(\mathrm{pPC}-\mathrm{H}_{2} \mathrm{O}\right)$ and in TFE (pPC-TFE) did not show significant $\mathrm{CD}$ signals (Figure 2d).

Naphthalenediimides (NDIs) are widely studied n-type organic semiconductors with potential applications in organicfield transistor, light harvesting systems, and photovoltaics. ${ }^{22}$ NDI $(\pi$-acidic with Qzz $=+18.6 \mathrm{~B})$ as $\pi$-electron acceptor (A) forms preferentially CT complex with $\pi$-electron donor pyrene (D). Owing to maximum overlap of $\mathrm{LUMO}_{\mathrm{NDI}}$ with $\mathrm{HOMO}_{\text {pyrene, }}$ NDI-pyrene CT complex can have large $K_{\mathrm{A}}$ values. ${ }^{23}$ Therefore, NDI was functionalized (Figures S4-9) to be compatible with the SPPS method and then was conjugated to a $\beta$-sheet forming hexapeptide sequence $\left(\mathrm{H}_{2} \mathrm{~N}\right.$ Ahx-VVAGEE-Am) to obtain a nPC molecule bearing negative charge $(\mathrm{S} 10-12)$. The $\mathrm{nPC}$ molecule was designed to have a similar molecular size, sequence, and complementary charge with pPC. The nPC in mild basic condition $\left(n P C-\mathrm{H}_{2} \mathrm{O}\right)$ and in TFE (nPC-TFE) demonstrated two absorption bands at 240 $\mathrm{nm}$ and in the range of $300-400 \mathrm{~nm}$, which are due to $\pi-\pi^{*}$ transitions polarized along the short and long axis of the NDI monomer, respectively (Figure S13a). ${ }^{24}$ A small bathochromic shift in NDI maxima (Figure S13a) was observed from TFE 

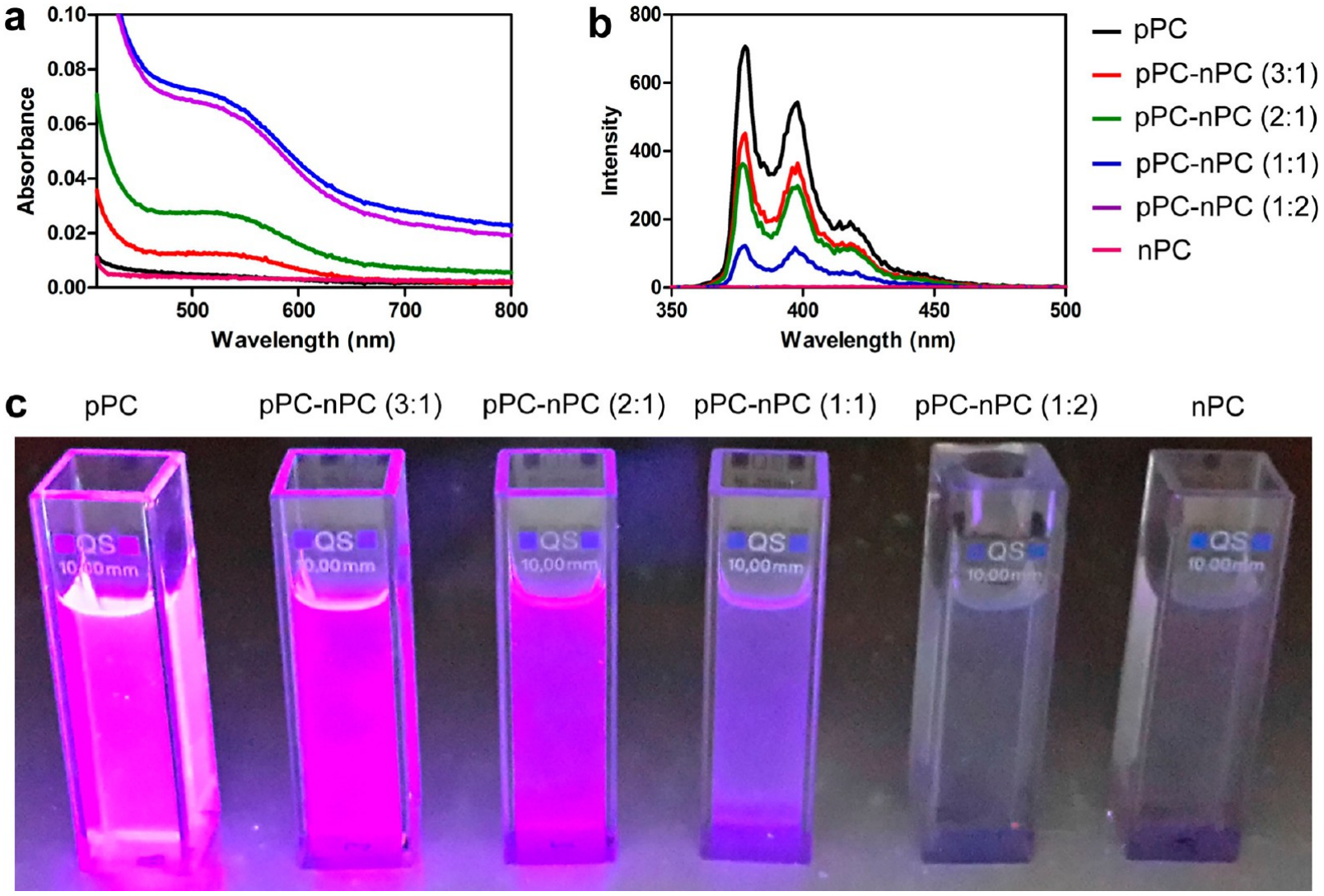

Figure 4. UV-vis absorption of CTC formation (a) and fluorescence quenching measurements (b) of pPC by nPC at different molar ratios. Quenching of pPC by nPC under $254 \mathrm{~nm}$ illumination (c).

(nPC-TFE) to $\mathrm{H}_{2} \mathrm{O}\left(\mathrm{nPC}-\mathrm{H}_{2} \mathrm{O}\right)$, which can be attributed to both solvent polarity difference and partial aggregation of amphiphilic nPC molecules in mild basic media despite charge repulsions caused by carboxylate groups $\left(\mathrm{COO}^{-}\right)$. Decreasing the $\mathrm{pH}$ to 2 (nPC-pH 2) caused an $8 \mathrm{~nm}$ red-shift, followed by shrinkage in absorption intensity in the range of 300-400 nm. Decrease in the absorption intensity and bathochromic shift in the absorption bands shows the presence of $J$-type $\pi-\pi$ interactions among NDI chromophores within n-type nanofibers. ${ }^{24}$ The nPA solution excited at $340 \mathrm{~nm}$ (Figure S13b) did not show any emission, and due to the electron-deficient character of NDI, we observed a very weak signal at $292 \mathrm{eV}$, which confirms the presence of $\pi-\pi$ stacking among NDI molecules within nPC nanofibers (Figure S13c).

We further investigated long-range organization of NDI chromophores within the supramolecular n-type nanofibers by carrying out $\mathrm{CD}$ spectroscopy of $\mathrm{nPC}$ in different conditions (Figure S13d). Partially assembled nPC in mild basic condition (nPC- $\left.\mathrm{H}_{2} \mathrm{O}\right)$ and in TFE (nPC-TFE) reveal weak signals in CD (Figure S13d). In contrast, acid triggered assembly of nPC (nPC-pH 2) demonstrated a strong excitonic Cotton effect in the range of $200-230 \mathrm{~nm}$ corresponding to highly ordered $\beta$ sheet secondary structures. Moreover, chiral signals between 240 and $400 \mathrm{~nm}$ were also observed due to $\pi-\pi^{*}$ transitions polarized along the short and long axis of the NDI monomer, verifying assembly of highly ordered chiral NDI chromophores within $\mathrm{nPC}$ nanofibers.

After investigation of individual self-assembly of $\mathrm{pPC}$ and $\mathrm{nPC}$ peptides in aqueous environment, we studied their coassembly, which formed a new hybrid material by utilizing hydrogen bonding, charge-transfer interactions, and electro- static attractions among positively charged amine groups $\left(\mathrm{NH}_{3}{ }^{+}\right)$of pPC and negatively charged carboxylate groups $\left(\mathrm{COO}^{-}\right)$of $\mathrm{nPC}$ nanofibers. When transparent solutions of $\mathrm{pPC}(\mathrm{pH} \sim 5)$ and $\mathrm{nPC}(\mathrm{pH} \sim 8)$ were mixed in a 1:1 ratio, a pink color solution was observed $(\mathrm{pH} \sim 7)$, which is an indication of formation of $\mathrm{pPC}-\mathrm{nPC}(\mathrm{n} / \mathrm{p}$-coassembled) CTC (Figure S14a). ${ }^{23}$ Similarly, UV-vis spectroscopy analysis of pPC-nPC in aqueous media demonstrated a new broad absorption band at $520 \mathrm{~nm}$, which is attributed to the chargetransfer (CT) band of NDI-pyrene (Figure 3a). ${ }^{23}$ Emission of highly fluorescent $\mathrm{pPC}$ nanofibers was quenched as soon as $\mathrm{nPC}$ nanofibers were mixed, which further confirms effective interaction between $\mathrm{pPC}$ and $\mathrm{nPC}$ and formation of $\mathrm{n} / \mathrm{p}$ coassembled CT complex (Figure 3b). Quenching of fluorescence was not followed by appearance of pyrene excimer emission, which is prevented by successful incorporation of NDI molecules between pyrene chromophores in $\mathrm{n} / \mathrm{p}$ coassembled CT complex. The $\pi-\pi$ stacking $(292 \mathrm{eV})$ present in the self-assembled $\mathrm{pPC}$ and $\mathrm{nPC}$ nanofibers disappeared when the CTC was formed between $\mathrm{pPC}$ and $\mathrm{nPC}$ moieties (Figure 3c). This further confirms the interaction of pyreneNDI molecules within $\mathrm{n} / \mathrm{p}$-coassembled CTC.

Coassembly of $\mathrm{pPC}$ and $\mathrm{nPC}$ nanofibers triggered by electrostatic attractions and CTC interactions was further studied by $\mathrm{CD}$ spectroscopy (Figure $3 \mathrm{~d}$ ). Individual solutions of $\mathrm{pPC}$ and $\mathrm{nPC}$ nanofibers revealed flat signals in $\mathrm{CD}$, while their coassembly via charge neutralization induced chiral signals. The signals at $220-230 \mathrm{~nm}$ confirm the presence of highly ordered $\beta$-sheet secondary structures. ${ }^{21}$ Moreover, we observed chiral peaks between 220 and $400 \mathrm{~nm}$, which are attributed to pyrene and NDI molecules. CD results revealed 

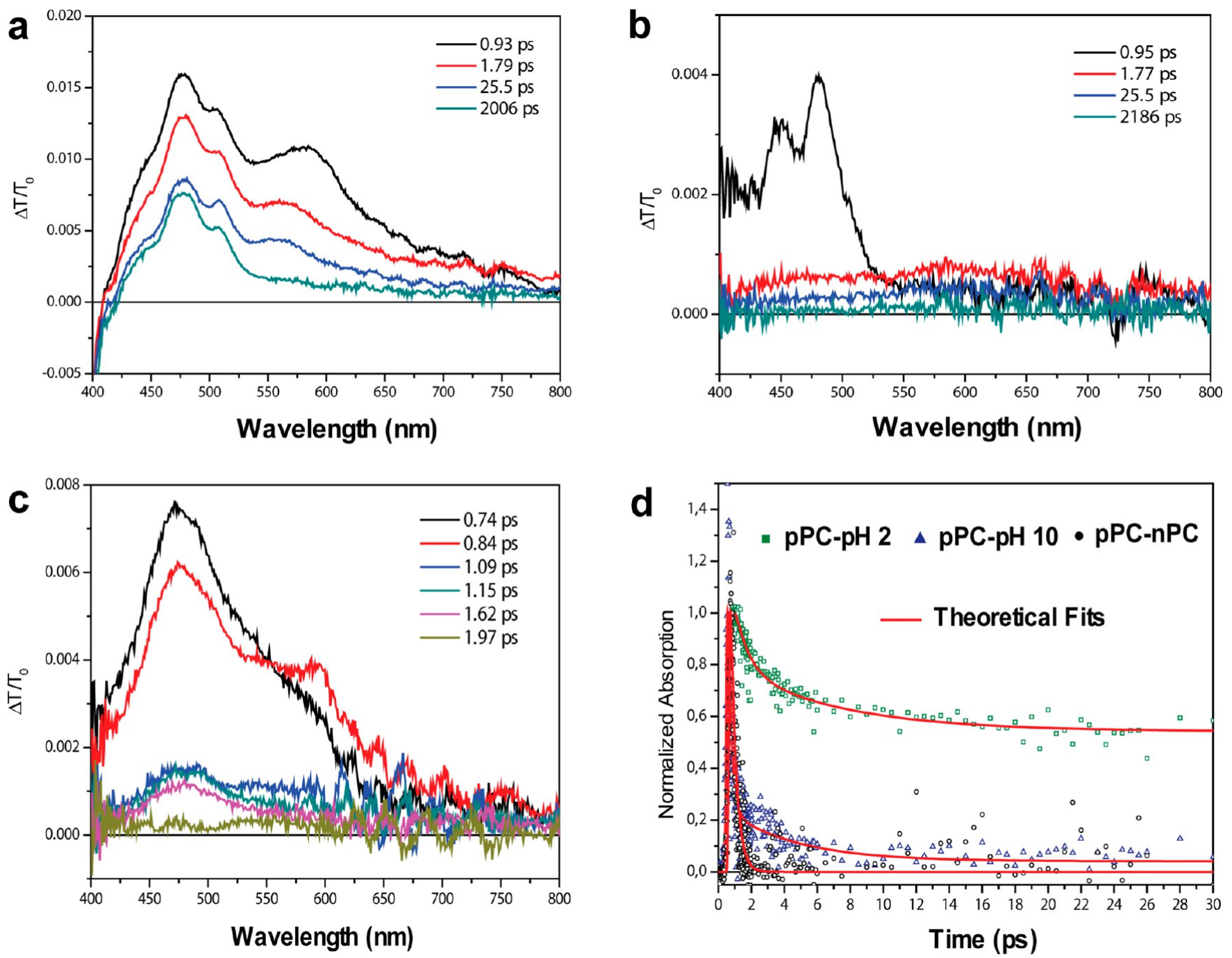

Figure 5. Transient absorption spectra of pPC-pH 2 with different time delays upon excitation at $340 \mathrm{~nm}$ (a). Transient absorption spectra of pPC-pH $10(b)$ and pPC-nPC (c) with different time delays upon excitation at $350 \mathrm{~nm}$. Decay curves of pPC-pH 2 and pPC-pH 10 samples and PPC-nPC CT complex pair at $477 \mathrm{~nm}$ probe wavelength (d).

that coassembly $\mathrm{pPC}$ and $\mathrm{nPC}$ into $\mathrm{n} / \mathrm{p}$-coassembled CTC induces chirality and long-range spatial organization to achiral pyrene and NDI molecules. Furthermore, CD spectroscopy of pPC and nPC coassembly showed that $\beta$-sheet signature and chiral signals in pPC-nPC solution are not merely a mathematical sum of individual CD spectra of $\mathrm{pPC}$ and $\mathrm{nPC}$ components (Figure 3d). This confirms that oppositely charged $\mathrm{pPC}$ and $\mathrm{nPC}$ nanofibers mix up and form a single aggregate structure. $^{25}$

We further performed titration experiments to assess how pPC and $\mathrm{nPC}$ molecules coassemble at different molar ratios. The $\mathrm{pPC}$ solutions of fixed concentrations were titrated with $\mathrm{nPC}$ solutions, and formation of CTC was monitored by UVvis and fluorescence spectroscopies (Figure 4). As the molar ratio of the $\mathrm{nPC}$ increases in the solution, the CT band at 520 $\mathrm{nm}$ increases (Figure 4a), and meanwhile emission of pyrene quenches (Figure 4b) until all pyrene molecules are complexed with NDI. Quenching of pPC by nPC can also be clearly observed with $254 \mathrm{~nm}$ illumination (Figure 4c).

Upon self-assembly, intermolecular charge transfer is expected to increase, causing the lifetime of the excited state absorption signals to reduce. ${ }^{26,27}$ We performed ultrafast pump-probe spectroscopy experiments to study the intermolecular charge transfer within $\mathrm{n} / \mathrm{p}$-coassembled CT complex (Figure 5). Partially aggregated pPC (pPC-pH 2), selfassembled $\mathrm{pPC}$ ( $\mathrm{pPC}-\mathrm{pH} 10)$, and $\mathrm{n} / \mathrm{p}$-coassembled ( $\mathrm{pPC}$ $\mathrm{nPC}$ ) samples were investigated. Pump wavelength was chosen based on the linear absorption spectra $(340-350 \mathrm{~nm})$, while white light continuum was used as the probe beam for all of the samples. A broad excited-state absorption signal was observed in the white light continuum spectra for all samples (Figure $5 \mathrm{a}-\mathrm{c})$, which is caused by aggregation of the samples.

Charge transfer between self-assembled pyrene molecules ( $\mathrm{pPC}-\mathrm{pH} 10)$ or between donor and acceptor chromophores (pPC-nPC) decreases electron population of the excited state, which is pumped. Therefore, not only the magnitude of excitedstate absorption signal $(\mathrm{S} 1 \rightarrow \mathrm{Sn})$ but also its lifetime are decreased (Figure $5 b-c$ ). Since charge transfer is very weak for pPC-pH 2, we observed a strong and broad ESA signal with a very long lifetime (Figure 5a). On the other hand, pPC-pH 10 and $\mathrm{pPC}-\mathrm{nPC}$ samples have strong charge transfers, and therefore, their relative ESA signals are very small compared to that of pPC-pH 2. In addition, the transient absorption spectra show that the ESA signal of pPC-pH 2 does not completely 
a

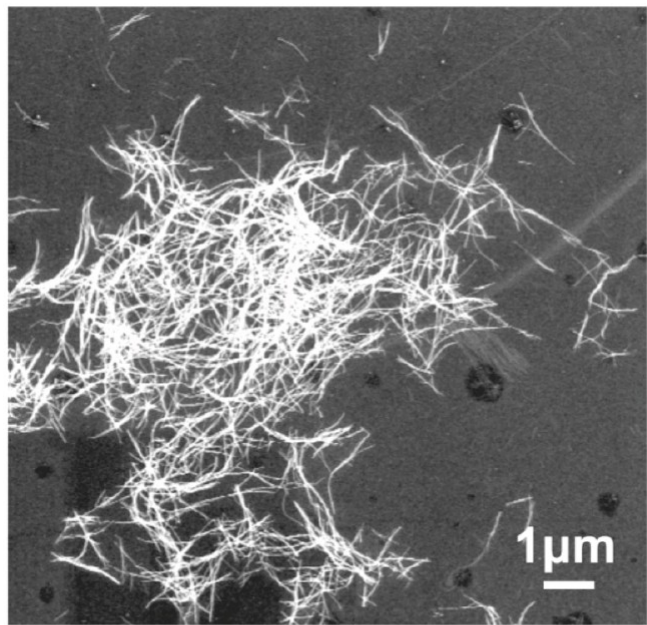

b

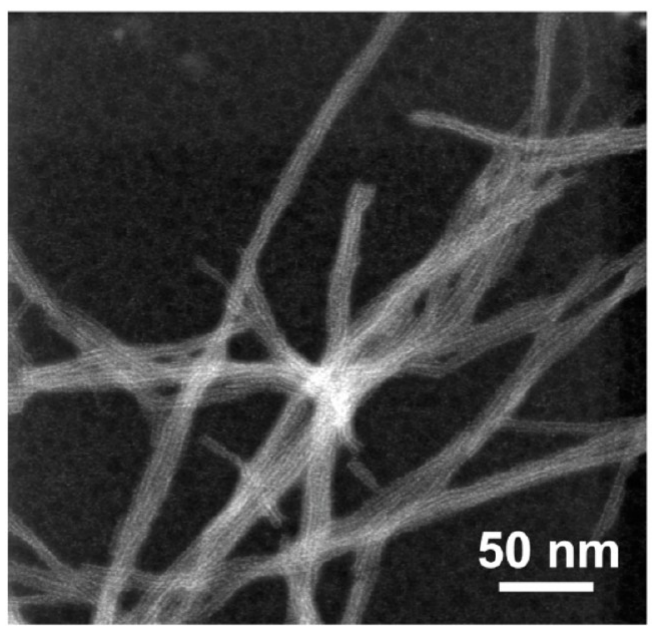

C

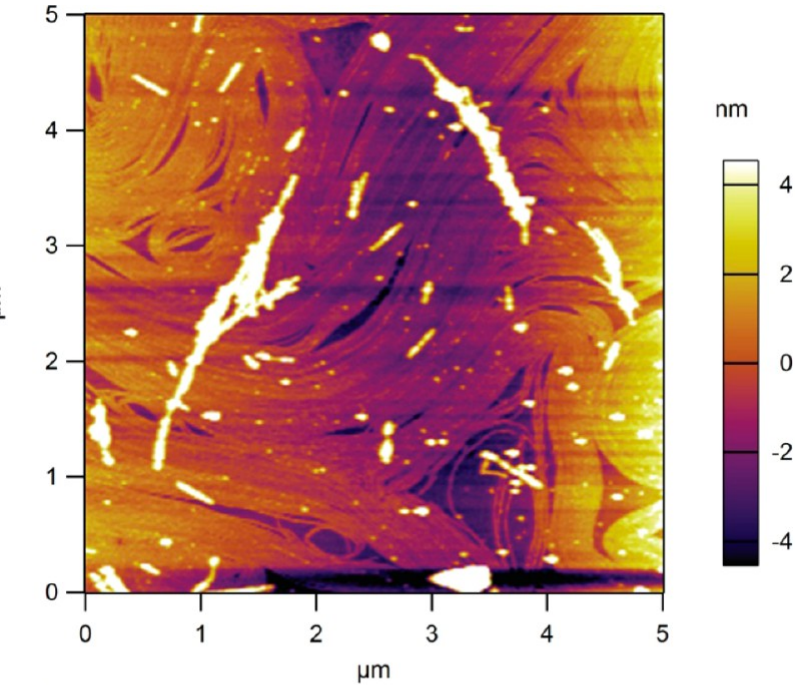

d

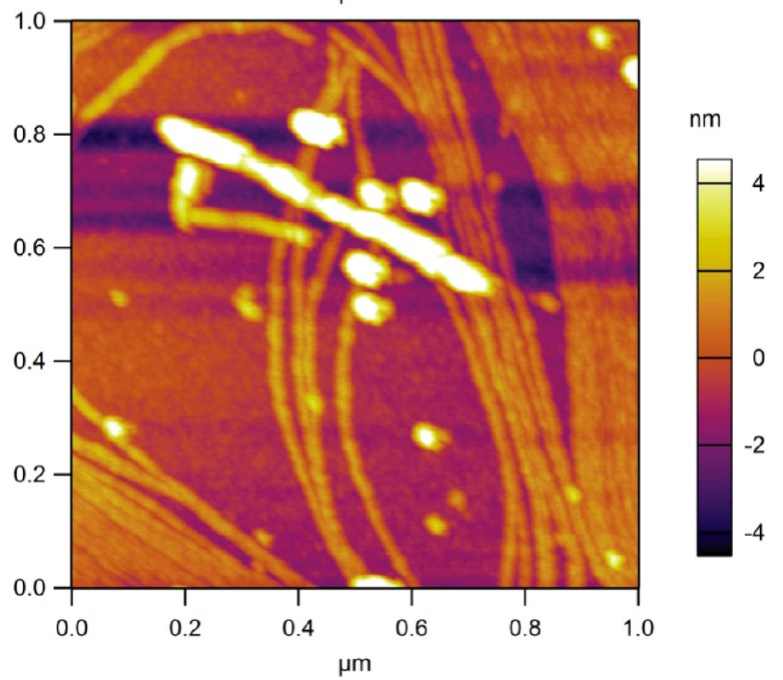

Figure 6. Imaging of $\mathbf{n} / \mathbf{p}$-coassembled CTC. STEM images ( $a$ and b) and AFM images (c and d) of $\mathbf{n} / \mathbf{p}$-coassembled supramolecular nanowires.

decay in $2 \mathrm{~ns}$, while that of pPC-pH 10 and pPC-nPC decays in 100 ps time delay (Figure 5a-c). Figure 5d shows decay curves of normalized excited-state absorption signal at $477 \mathrm{~nm}$ probe. Decay time components were measured as $7 \mathrm{ps}, 4 \mathrm{ps}$, and 300 fs for samples pPC-pH 2, pPC-pH 10, and pPC-nPC, respectively. A faster decay of the excited-state absorption signal of $\mathrm{pPC}-\mathrm{pH} 10$, than that of $\mathrm{pPC}-\mathrm{pH} 2$, is an indication of aggregation at high $\mathrm{pH}$. Furthermore, the fastest decay time component ( $300 \mathrm{fs}$ ) of pPC-nPC CTC within the investigated samples is the indication of stronger charge transfer among $\mathrm{pPC}$ and $\mathrm{nPC}$ molecules. These results are in good agreement with the fluorescence experiments showing that the coassembly process causes fluorescence quenching of the investigated pPCnPC CT complex.

STEM images of positively stained supramolecular $\mathrm{n} / \mathrm{p}$ coassembled CTC reveal a network of highly uniform nanofibrous morphology with a diameter of $10 \pm 1 \mathrm{~nm}$ and microns long in length (Figure $6 \mathrm{a}-\mathrm{b}$ ). These results confirmed that the average diameter of $\mathrm{n} / \mathrm{p}$-coassembled supramolecular nanowires is similar to those of individual $\mathrm{pPC}$ and $\mathrm{nPC}$ nanofibers. Moreover, imaging of dried $n / p$-coassembled nanowires samples by atomic force microscopy (AFM) also exhibited formation of highly uniform nanofibrous morphology with height in nanometers and length in microns (Figure 6c- d). Self-assembling peptides can form nanostructures due to evaporation of water. We also performed contact-mode AFM imaging in solution to reveal $\mathrm{n} / \mathrm{p}$-coassembled nanowires are present in the aqueous media. The AFM images at high (27 $\mu \mathrm{M})$ and low concentrations $(3 \mu \mathrm{M})$ of pPC-nPC exhibited highly uniform nanofibrous morphology of $n / p$-coassembled nanowires in solution (Figure S15). The dried n/pcoassembled samples imaged by STEM and AFM exhibiting uniform nanofibers are similar to the ones observed in the solution.

To investigate in depth molecular interactions between pPC and nPC, XPS, FT-IR, and nuclear Overhauser effect spectroscopy (NOESY) were conducted to study the efficient electrostatic interactions between positively charged amine groups $\left(\mathrm{NH}_{3}{ }^{+}\right)$of the pPC and negatively charged carboxylate groups $\left(\mathrm{COO}^{-}\right)$of the $\mathrm{nPC}$ within $\mathrm{n} / \mathrm{p}$-coassembled supramolecular nanowires. The pink suspension of $n / p$-coassembled nanowires was centrifuged at $8500 \mathrm{rpm}$, and the upper solution part was decanted, followed by addition of fresh water and centrifuged again. This procedure was repeated several times to get rid of any uncomplexed pPC and nPC molecules and then lyophilized to get a pink powder (Figure S14b). XPS analysis of the pPC powder shows the existence of $\mathrm{F} 1 \mathrm{~s}$ at $689 \mathrm{eV}$ (Figure S16a), which corresponds to presence of the counterion 
trifluoroacetate anion $\left(\mathrm{TFA}^{-}\right){ }^{28}$ Meanwhile, $\mathrm{nPC}$ powder shows $\mathrm{Na} 1 \mathrm{~s}$ at $1072 \mathrm{eV}$ (Figure S16b) which is attributed to the presence of counterion sodium cation $\left(\mathrm{Na}^{+}\right)$. On the other hand, no significant signal at $689 \mathrm{eV}$ (F 1s) and $1072 \mathrm{eV}(\mathrm{Na}$ 1s) in $\mathrm{n} / \mathrm{p}$-coassembled CTC powder (Figure S16c) was observed, which is due to efficient electrostatic interactions between $\mathrm{NH}_{3}{ }^{+}$and $\mathrm{COO}^{-}$groups where $\mathrm{Na}^{+}$and $\mathrm{TFA}^{-}$form a soluble sodium trifluoroacetate salt, which is washed away during centrifugation steps. FTIR measurements further confirmed the removal of sodium trifluoroacetate during washings, as the $\mathrm{C}-\mathrm{F}$ stretching mode $\left(1110-1220 \mathrm{~cm}^{-1}\right)$ completely disappeared in $\mathrm{n} / \mathrm{p}$-coassembled CTC powder (Figure S16d). ${ }^{29}$ To further elucidate the electrostatic interactions within $\mathrm{n} / \mathrm{p}$-coassembled nanowires, we carried out $2 \mathrm{D}$ NOESY, which is a powerful nuclear magnetic resonance (NMR) technique for structural studies. When a proton is close in space ( $>5 \AA$ ) to another proton (or any other nuclei with spin $>0$ ), their magnetic dipoles interact, therefore it can be easily detected by NOESY technique. A typical distance between $\mathrm{D}-\mathrm{A} \mathrm{CTC}$ and $\beta$-sheet structure is approximately in the range of 3-5 $\AA$. Hence, interacting protons of the $\mathrm{pPC}$ with the $\mathrm{nPC}$ are within this range and can easily be detected. We observed close contacts $(<3 \AA)$ between Glu- $\mathrm{H}_{\beta}$ protons of $\mathrm{nPC}$ and $\mathrm{Lys}-\mathrm{H}_{\varepsilon}$ protons of $\mathrm{pPC}$ (Figure S17), which further proved that the $\mathrm{pPC}$ and the $\mathrm{nPC}$ are positioned in close proximity by electrostatic interactions within the supramolecular $\mathrm{n} / \mathrm{p}$-coassembled nanowires. ${ }^{25}$

Pyrene and NDI moieties can form a variety of CT complexes in different molecular structures such as A-D, D$\mathrm{A}-\mathrm{D}$, and $\mathrm{A}-\mathrm{D}-\mathrm{A}$, where each $\mathrm{CT}$ complex has specific thermodynamic parameters and $K_{\mathrm{A}}$ values. ${ }^{30,31} \mathrm{UV}$-vis, XPS, mass spectrometry (MS), and isothermal titration calorimetry (ITC) were carried out to determine the accurate molecular structure of CT complex and its $K_{\mathrm{A}}$ value. We used the Job's method to estimate the stoichiometry of pPC-nPC. ${ }^{32}$ Solutions of the $\mathrm{PPC}$ and the $\mathrm{nPC}$ were mixed in known ratios to form the CT complex where the total concentrations of the $\mathrm{pPC}$ and the $\mathrm{nPC}$ in solution were kept constant (Figure S18). Absorbance at $520 \mathrm{~nm}$ (CT band) was plotted against the molar ratio of the $\mathrm{nPC}$, and the maximum absorbance value intersecting $x$-axis corresponds to the stoichiometry of $\mathrm{D}-\mathrm{A}$ (Figure S18b). The two maxima show the presence of two different CTC including pPC-nPC (1:1) and pPC-nPC (1:2).

Gaussian deconvolution of the N-1s signal can be exploited to determine the populations of electronically distinct $\mathrm{N}$ atoms in pPC-nPC CTC. ${ }^{12}$ Deconvolution of the total $\mathrm{N}$ 1s signal intensity (Figure $7 \mathrm{a}$ ) reveals $7 \%$ of $\mathrm{N}$ atoms arising from protonated amines $\left(\mathrm{R}^{\prime \prime}-\mathrm{NH}_{3}{ }^{+}\right)$and $93 \%$ of $\mathrm{N}$ atoms arising from amide groups ( $\left.\mathrm{R}^{\prime}-\mathrm{NHR}\right)$ in $\mathrm{pPC}-\mathrm{nPC} \mathrm{CTC}$. In order to determine the binding ratio of $\mathrm{pPC}$ to $\mathrm{nPC}$ according deconvolution results, we needed to construct such a CTC with $7 \%$ of $\mathrm{N}$ atoms that are protonated $\left(\mathrm{R}^{\prime \prime}-\mathrm{NH}_{3}{ }^{+}\right)$and $93 \%$ of $\mathrm{N}$ atoms that arise from amide groups ( $\left.\mathrm{R}^{\prime}-\mathrm{NHR}\right)$. Only the CT complex with pPC-nPC (1:2) structure satisfies the deconvolution results (Figure S19). Mass spectrometry of pPC-nPC CT complex shows a signal at $1582 \mathrm{~m} / z$, which further supports that $\mathrm{pPC}$ molecules are sandwiched between two nPC molecules (nPC-pPC-nPC) (Figure S20). Results obtained from spectroscopic techniques verify the presence of pPC-nPC (1:2) unit cells within $\mathrm{n} / \mathrm{p}$-coassembled nanowires.

ITC was performed to further support the spectroscopic results. A very strong association constant of $\left(K_{\mathrm{A}}\right)$ of $5.18 \times 10^{5}$ $\mathrm{M}^{-1}$, enthalpy $(\Delta H)$ of $-7215 \mathrm{cal} / \mathrm{mol}$ and entropy $(\Delta S)$ of

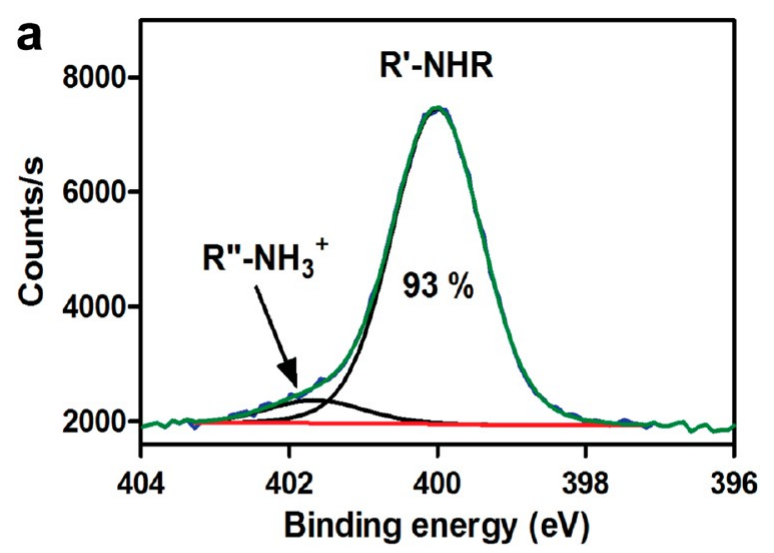

b Time (min)

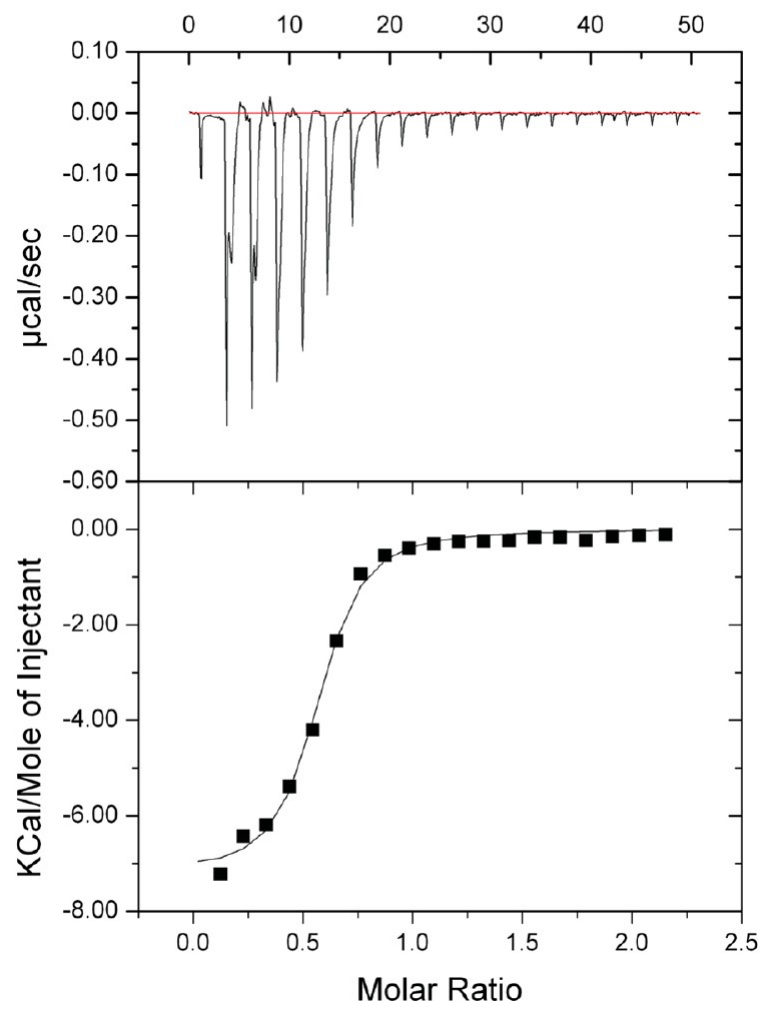

Figure 7. Gaussian deconvolution of the $\mathrm{N}$ 1s signal of pPC-nPC CTC acquired by XPS (a). Isothermal calorimetry titration of nPC $(0.1 \mathrm{mM})$ by pPC $(1 \mathrm{mM})$ and binding isotherm of heat of formation against molar ratio of $\mathrm{pPC} / \mathrm{nPC}(\mathrm{b})$.

$1.95 \mathrm{cal} / \mathrm{mol} \mathrm{deg}$ were calculated from isothermal titrations (Figure $7 \mathrm{~b}$ ). Owing to synergic interactions arising from charge-transfer formation, hydrogen bonding, and electrostatic interactions between the $\mathrm{pPC}$ and the $\mathrm{nPC}$ molecules, a very strong $K_{\mathrm{A}}$ value was obtained for $\mathrm{n} / \mathrm{p}$-coassembled nanowires. A negative Gibbs energy $(-\Delta G)$ can easily be calculated from measured $\Delta H$ and $\Delta S$ values, which confirms highly favorable coassembly of $\mathrm{pPC}$ and $\mathrm{nPC}$ nanofibers to form $\mathrm{n} / \mathrm{p}$ coassembled nanowires in aqueous medium. Moreover, a ratio of 1:2 was also calculated for the $\mathrm{pPC}$ : $\mathrm{nPC}$ from binding isotherm of heat of formation against molar ratio of $\mathrm{pPC} / \mathrm{nPC}$ (Figure 7b).

In addition, we further investigated the role of Coulombic attractions and charge-transfer interactions as key driving forces to form $\mathrm{n} / \mathrm{p}$-coassembled nanowires. Therefore, we synthesized 
a
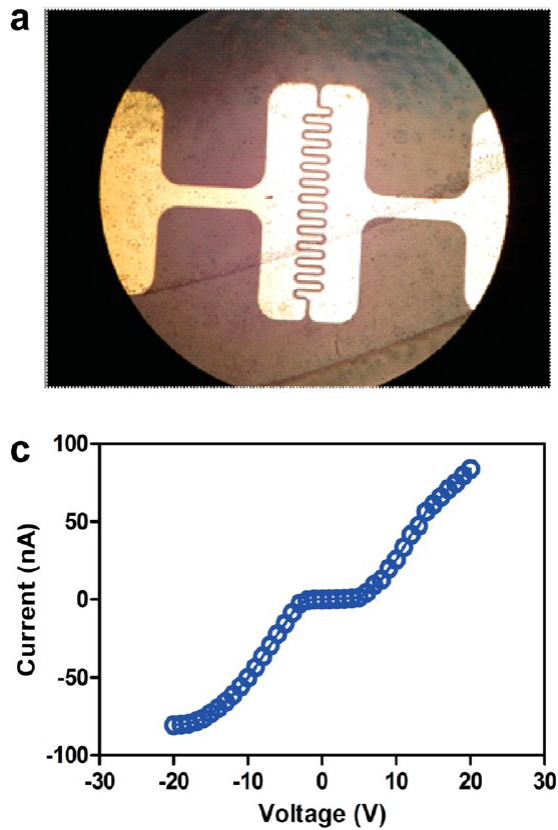

b

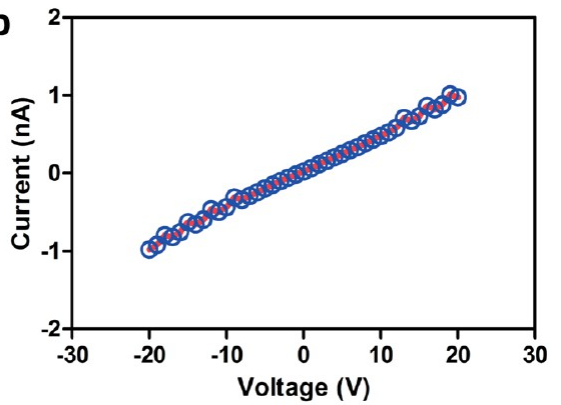

d

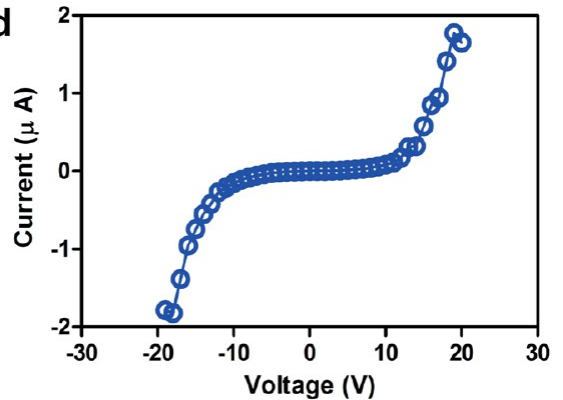

Figure 8. Optical microscope image of a single device after forming Au contacts (a). Current-voltage (I-V) characteristics of the nPC (b), pPC (c), and the pPC-nPC films (d). Red line is the regression line for the $I-V$ curve measured for the $\mathrm{nPC}$ film.

a new peptide molecule (nPA2), which is analogous to $\mathrm{nPC}$ but with positive charge (Figure S21-23). Uranyl acetate stained nPC2 sample was imaged by transmission electron microscope (TEM) showing a diameter of $11 \pm 1 \mathrm{~nm}$ and microns in length (Figure S24). All peptide molecules ( $\mathrm{pPC}, \mathrm{nPC}$, and nPC2) showed similar nanofibrous morphology with diameters of $11 \pm 1 \mathrm{~nm}$ and microns in length. When a solution of $\mathrm{pPC}$ is mixed with nPC2 into 1:1 ratio (pPC-nPC2), we observed a pale purple color, which is evidence for the formation of CTC, but the color change is not as intense as in case of pPC-nPC with the same concentration (Figure S25a). In the absence of electrostatic attractions (pPC-nPC2), the CT band shows an absorbance of 0.01 (Figure S25b), while in the presence of Coulombic attractions (pPC-nPC), the CT band jumps to 0.05 absorbance intensity (Figure S25b). This experiment provides valuable information regarding the coassembly process. The supramolecular p-type and n-type nanofibers are highly dynamic in nature, and there is exchange of $\mathrm{pPC}$ and $\mathrm{nPC} 2$ molecules within the nanofibers to form CTC in the absence of electrostatic interactions. The UV-vis absorption spectra (Figure S25b) clearly showed that we have low concentrations of pPC-nPC2 CTC in addition to high concentrations of uncomplexed pPC and nPC2 molecules. These pPC and nPC2 molecules can further self-assemble randomly into a variety of aggregates. ${ }^{33}$ In the presence of Coulombic attractions (pPC$\mathrm{nPC}$ ), we observed that there is a 5 -fold increase in absorbance of pPC-nPC CTC, which means that a majority of the $\mathrm{pPC}$ and $\mathrm{nPC}$ molecules participate in the formation of a CTC. The major driving force for the formation of $n / p$ - coassembled nanowires is Coulombic attractions, while charge-transfer interactions contribute slightly. ${ }^{15}$ In other words, electrostatic interactions significantly improve the formation of CTC between pyrene and NDI moieties within $\mathrm{n} / \mathrm{p}$-coassembled nanowires. The $\mathrm{pPC}-\mathrm{nPC}$ and $\mathrm{pPC}-\mathrm{nPC} 2$ have different absorption profiles (Figure S25b) and solution colors (Figure S26), because the coassembly process in both cases produces different CTC. The mass spectrum of $\mathrm{pPC}-\mathrm{nPC}$ exhibits a signal at $1582 \mathrm{~m} / z$, whereas pPC-nPC2 exhibits a signal at 2072 $\mathrm{m} / z$ (Figure S25c). These results reveal the formation of pPCnPC (1:2) CTC in the presence of Coulombic attractions and pPC-nPC2 (1:1) CTC in the absence of Coulombic attractions. We can conclude that Coulombic attractions are primarily responsible for the formation of $\mathrm{n} / \mathrm{p}$-coassembled nanowires which mainly consist of highly ordered nPC-pPC-nPC stacks.

Materials forming CT states can show improved conductivity. ${ }^{13}$ Therefore, the conductivity of $\mathrm{pPC}, \mathrm{nPC}$, and pPC-nPC films was measured at room temperature using a twoprobe technique. Peptide nanofiber films were deposited on precleaned glass substrates by drop casting peptide solutions, followed by drying at $37^{\circ} \mathrm{C}$ under vacuum for $24 \mathrm{~h}$. The metal contacts were formed by securing the shadow masks with channel lengths of 10 and $20 \mu \mathrm{m}$ (Figure S27) on top of the samples. Then gold films were deposited in a thermal evaporator system on the areas of the samples that are not protected by the shadow masks (Figure 8a and Figure S28). The electrical resistance of the films between the contacts was measured by sweeping the voltage on one pad from -20 to 20 $\mathrm{V}$ and fixing the other pad's voltage at $0 \mathrm{~V}$ while measuring the electrical current from each probe. For an ideal resistor, the current-voltage $(I-V)$ curve is expected to be linear. The resistance can be calculated as the inverse of the slope for the linear regression curve. The $I-V$ characteristics of the nPC film exhibit such an ideal resistor behavior (Figure $8 \mathrm{~b}$ ).

However, $I-V$ curves for the pPC (Figure $8 \mathrm{c}$ ) and the pPCnPC (Figure 8d) films are nonlinear suggesting a Schottky barrier between the films and the Au contacts. ${ }^{34}$ The Schottky barrier limits the electrical conduction for low electric field levels, thus the resistance readings are taken for large electric field/voltage levels $(15-20 \mathrm{~V})$ for these samples. Unlike the resistance, the resistivity is an intrinsic property of the material and does not depend on the device geometry. Hence, the film resistivity values are calculated using the measured resistance values and the device dimensions. The resistance can be modeled as $\rho L / W t$ for any resistor with a uniform cross- 
section, where $\rho$ is the resistivity, $L$ is the channel length, $W$ is the channel width, and $t$ is the film thickness which is obtained from AFM images (Figure S29). Table S2 summarizes the values of three devices for each peptide film and compares the final resistivity and conductivity values. The conductivities of $\mathrm{nPC}$ and $\mathrm{pPC}$ films are $7.6 \times 10^{-9} \mathrm{~S} / \mathrm{cm}$ and $1.97 \times 10^{-6} \mathrm{~S} / \mathrm{cm}$, respectively. Interestingly, $\mathrm{pPC}-\mathrm{nPC}$ films demonstrate enhanced conductivity of $1.65 \times 10^{-5} \mathrm{~S} / \mathrm{cm}$, which is approximately 2400 times more conductive than nPC films and 10 times more than pPC films. The enhancement in conductivity of $\mathrm{pPC}-\mathrm{nPC}$ films can be attributed to strong intermolecular charge-transfer interactions between pyrene and NDI moieties to form CT states within $\mathrm{n} / \mathrm{p}$-coassembled nanowires. $^{11,13}$

\section{CONCLUSIONS}

In summary, we presented self-assembling p-type and n-type peptide-chromophore conjugates. Positively charged $\mathrm{pPC}$ and negatively charged $\mathrm{nPC}$ molecules individually assembled into highly uniform p-type and n-type nanofibers, respectively, with a diameter of $11 \pm 1 \mathrm{~nm}$ and microns in length. These complementary p-type and n-type nanofibers coassembled via hydrogen bonding, charge-transfer interactions, and electrostatic interactions to generate highly uniform supramolecular $n$ / p- coassembled 1D nanowires. It was shown that Coulombic attractions are primarily responsible for the formation of $n / p$ coassembled nanowires in aqueous media. We also demonstrated that supramolecular $\mathrm{n} / \mathrm{p}$-coassembled nanowires are formed from nPC-pPC-nPC unit cells having a strong $K_{\mathrm{A}}$ of $5.18 \times 10^{5} \mathrm{M}^{-1}$. Moreover, electrical measurements revealed that supramolecular $\mathrm{n} / \mathrm{p}$-coassembled nanowires are about 2400 and 10 times more conductive than individual n-type and p-type nanofibers, respectively. This facile strategy allows fabrication of well-defined supramolecular electroactive nanomaterials in aqueous media, which can find a variety of applications in optoelectronics, photovoltaics, and bioelectronics.

\section{METHODS/EXPERIMENTAL}

Synthesis of Peptide Molecules. All peptide molecules were synthesized by using solid-phase peptide synthesis (SPPS) method. The syntheses were performed on MBHA rink amide resin and 2 equiv of fluorenylmethyloxycarbonyl (fmoc) protected amino acids, 1.95 equiv of $o$-benzotriazole- $N, N, N^{\prime}, N^{\prime}$-tetramethyl-uroni $\mu$ m-hexafluorophosphate (HBTU), and 3 equiv of $\mathrm{N}, \mathrm{N}$-diisopropylethylamine (DIEA) for $6 \mathrm{~h}$. Fmoc protecting groups were removed by $20 \%$ of piperidine in dimethylformamide for $20 \mathrm{~min}$. The peptides were cleaved from the solid resin by a mixture of trifluoroacetic acid:triisopropylsilane: $\mathrm{H}_{2} \mathrm{O}$ in the ratio of $95: 2.5: 2.5$ for $2 \mathrm{~h}$. The product was collected into a round-bottom flask by washing the resin with DCM. The DCM was evaporated by rotary evaporation, and cold ether was poured to precipitate the peptide. The final product was collected by centrifuging and then lyophilizing for $72 \mathrm{~h}$ to get white powder. In the last step of the synthesis, 2 equiv of commercial available 1-pyrenebutyric acid was used, and the coupling was left for $24 \mathrm{~h}$ to get pPC. For nPC and nPC2 peptides syntheses, 1.5 equiv of $n$-Bu-NTA- $\beta$ alanine was used, and the coupling was left for $24 \mathrm{~h}$.

Preparative High-Performance Liquid Chromatography (prep-HPLC). In purification of positively charged peptide molecules, reverse-phase silica column $(\mathrm{C} 18)$ and $0.1 \%$ TFA in water and $0.1 \%$ in ACN were used as the mobile phase, while negatively charged peptide molecules were eluted by $0.1 \% \mathrm{NH}_{4} \mathrm{OH}$ in water and $0.1 \% \mathrm{NH}_{4} \mathrm{OH}$ in ACN. A preparative liquid chromatography system (prep-HPLC Agilent 1200 series) integrated with a sample collector was used.
Liquid Chromatography-Mass Spectrometry (LC-MS). After purification of the peptide molecules by prep-HPLC, the purity of the molecules was determined by Agilent Technologies 6530 AccurateMass Q-TOF LC-MS. A Zorbax SB-C18 column and 0.1\% formic acid in water and $0.1 \%$ formic acid in acetonitrile were used as mobile phase for positively charged molecules and $0.1 \% \mathrm{NH}_{4} \mathrm{OH}$ in water and $0.1 \% \mathrm{NH}_{4} \mathrm{OH}$ in $\mathrm{ACN}$ were used for negatively charged peptide molecules.

UV-vis Spectroscopy. The peptide solutions were prepared in a $3 \mathrm{~mL}$ quartz cell with a $1 \mathrm{~cm}$ path length. Stock solution of pPC was prepared by dissolving $2 \mathrm{mg}$ of pPC in $200 \mu \mathrm{L}$ of water. Three $\mathrm{mL}$ of pPC with a concentration of $55 \mu \mathrm{M}$ was prepared from stock solution. For nPC peptide, $1.6 \mathrm{mg}$ of molecule was dissolved in $140 \mu \mathrm{L}$ of $1 \mathrm{mM}$ $\mathrm{NaOH}$ plus $25 \mu \mathrm{L}$ of $0.5 \mathrm{M} \mathrm{NaOH}$. Three $\mathrm{mL}$ of $\mathrm{nPC}$ with a concentration of $55 \mu \mathrm{M}$ was prepared from stock solution. The dilutions were performed by $1 \mathrm{mM} \mathrm{NaOH}$ to keep the $\mathrm{pH}$ around 8 . The absorbance was recorded on a CaryBio100 instrument.

Fluorescence Spectroscopy. The peptide solutions were prepared in a $3 \mathrm{~mL}$ quartz cell with a $1 \mathrm{~cm}$ path length. Stock solution of pPC was prepared by dissolving $2 \mathrm{mg}$ of pPC in $200 \mu \mathrm{L}$ of $\mathrm{dd}$ water. Three $\mathrm{mL}$ of $\mathrm{pPC}$ with a concentration of $55 \mu \mathrm{M}$ was prepared from stock solution. For nPC peptide, $1.6 \mathrm{mg}$ of molecule was dissolved in $140 \mu \mathrm{L}$ of $1 \mathrm{mM} \mathrm{NaOH}$ plus $25 \mu \mathrm{L}$ of $0.5 \mathrm{M} \mathrm{NaOH}$. Three $\mathrm{mL}$ of $\mathrm{nPC}$ with a concentration of $55 \mu \mathrm{M}$ was prepared from stock solution. The dilutions were performed by $1 \mathrm{mM} \mathrm{NaOH}$ solution to keep the $\mathrm{pH}$ around 8 . The samples were excited at 340 $\mathrm{nm}$, and excitation slit and emission slit widths were adjusted to 1.5 and 5, respectively. The emission intensities were recorded on a Cary Eclipse fluorescence spectrometer instrument.

Circular Dichroism (CD) Spectroscopy. The peptide solutions were prepared in a $3 \mathrm{~mL}$ quartz cell with a $1 \mathrm{~cm}$ path length. Stock solution of pPC was prepared by dissolving $2 \mathrm{mg}$ of pPC in $200 \mu \mathrm{L}$ of $\mathrm{dd}$ water. Three $\mathrm{mL}$ of $\mathrm{pPC}$ with a concentration of $55 \mu \mathrm{M}$ was prepared from stock solution. For nPC peptide, $1.6 \mathrm{mg}$ of molecule was dissolved in $140 \mu \mathrm{L}$ of $1 \mathrm{mM} \mathrm{NaOH}$ plus $25 \mu \mathrm{L}$ of $0.5 \mathrm{M} \mathrm{NaOH}$. Three $\mathrm{mL}$ of $\mathrm{nPC}$ with a concentration of $55 \mu \mathrm{M}$ was prepared from stock solution. The dilutions were performed by $1 \mathrm{mM} \mathrm{NaOH}$ to keep the $\mathrm{pH}$ around 8 . The samples were measured from 500 to $190 \mathrm{~nm}$ with 0.1 data pitch, $100 \mathrm{~nm} / \mathrm{min}$ scanning speed, $1 \mathrm{~nm}$ bandwidth, and 4 s D.I.T. An average of two measurements were adjusted, and sensitivity was selected as standard. All measurements were recorded on a Jasco J-815 CD spectrometer.

X-ray Photoelectron Spectroscopy (XPS). Solutions of pPC and $\mathrm{nPC}$ were prepared in $\mathrm{dd}$ water, then they were mixed into $1: 1$ mol ratio to form a reddish suspension (Figure S14a). The suspension was centrifuged at $8500 \mathrm{rpm}$ for $10 \mathrm{~min}$, and the upper part was decanted. Then fresh dd water was added followed by centrifugation. This process was performed for seven times to remove any unbound pPC and nPC molecules. The peptide suspension was freeze-dried to obtain reddish powder. This powder was analyzed by Thermo K-alpha monochromatic high-performance X-ray photoelectron spectrometer. The survey analyses were performed at 10 scans.

Coassembly of pPC and nPC (Titrations). Six different solutions were prepared where the mole of the $\mathrm{pPC}$ was kept at $1.65 \times 10^{-7}(55$ $\mu \mathrm{M}, 3 \mathrm{~mL}$ ) and the mole ratio of $\mathrm{nPC}$ was changed. The mole ratios are as follow: pPC:nPC (1:0), (3:1), (2:1), (1:1), (2:1), and (0:1). The CTC formation was monitored by UV-vis and fluorescence spectroscopy. The samples were excited at $340 \mathrm{~nm}$, and excitation slit and emission slit widths were adjusted to 1.5 and 5 , respectively. The $\mathrm{pH}$ of the final solution for $\mathrm{pPC}-\mathrm{nPC}$ is always around 7.

Ultrafast Pump-Probe Spectroscopy. The ultrafast wavelength-dependent pump probe spectroscopy measurements were performed using a Ti:Sapphire laser amplifier-optical parametric amplifier system (Spectra Physics, Spitfire Pro XP, TOPAS) with commercial pump probe setup (Spectra Physics, Helios). Pulse duration was measured as $100 \mathrm{fs}$ with a cross correlation. Wavelengths of the pump beam were $340 \mathrm{~nm}$ for pPC molecules and $350 \mathrm{~nm}$ for pPC-nPC CT complex. White light continuum was used as a probe beam. 
Scanning Transmission Electron Microscopy (STEM). FEI Tecnai G2 F30 transmission electron microscope (TEM) was used to image the stained ( $2 \%$ uranyl acetate solution) peptide nanofibers. Ten $\mu \mathrm{L}$ of peptide solutions prepared for $\mathrm{UV}$-vis and fluorescence spectroscopies were dropped on a carbon-covered copper grid followed by air drying at temperature. The stainings were performed for $90 \mathrm{~s}$.

Atomic Force Microscopy (AFM). Solutions of $\mathrm{pPC}$ and $\mathrm{nPC}$ were prepared in dd water, then they were mixed into $1: 1 \mathrm{~mol}$ ratio to form a reddish suspension. The suspension was diluted 100 times, and $10 \mu \mathrm{L}$ of was dropped on clean silicon wafer. The dried sample was imaged by noncontact mode using a MFP3D Asylum microscope. For imaging of pPA-nPA samples in solution, stock solutions of pPA (55 $\mu \mathrm{L})$ and $\mathrm{nPA}(55 \mu \mathrm{L})$ were prepared. After mixing and vortexing, 300 $\mu \mathrm{L}$ of the sample was added onto freshly cleaved mica and imaged in aqueous environment with contact mode. Silicon nitride soft contact mode AFM probes $(\mathrm{SiNi})$ from Budget Sensors were used for the imaging.

Fourier Transform Infrared (FT-IR) Spectroscopy. Samples prepared for XPS analyses were pressed into $\mathrm{KBr}$ pellets. Only the $\mathrm{KBr}$ pellet was used as background. The measurements were recorded on Fourier transform infrared spectrometer (Bruker VERTEX 70). 64 scans were recorded between 4000 and $400 \mathrm{~cm}^{-1}$ at a resolution of 4 $\mathrm{cm}^{-1}$.

Nuclear Overhauser Effect Spectroscopy (NOESY). Six mg of pPC was dissolved in $\mathrm{D}_{2} \mathrm{O}$, and $6 \mathrm{mg}$ of $\mathrm{nPC}$ was dissolved in $500 \mu \mathrm{L}$ of $\mathrm{D}_{2} \mathrm{O}+150 \mu \mathrm{L}$ of $\mathrm{NaOD}$ (30\% solution). The pPC and nPC solutions were mixed, and NOESY spectrum was recorded at 64 scans using $400 \mathrm{MHz}$ NMR.

Isothermal Titration Calorimetry (ITC). $0.1 \mathrm{mM}$ of $\mathrm{nPC}(280$ $\mu \mathrm{L})$ solution was titrated by $1 \mathrm{mM}$ of $\mathrm{pPC}(40 \mu \mathrm{L})$ solution using iTC200 system (MicroCal, GE Healthcare). The titration was performed at $25{ }^{\circ} \mathrm{C}$ with $400 \mathrm{rpm}$ stirring speed. Reference power was set as $5 \mu \mathrm{Cal} / \mathrm{s}$. Twenty injections were done, where the injection period was $4 \mathrm{~s}$ and the space between injections was $150 \mathrm{~s}$. ITC binding isotherms were best fitted by a one-sets of site mode.

Electrical Measurements. Shadow masks from the Ossila Inc. are used with channel lengths of 10 and $20 \mu \mathrm{m}$ and widths on the order of approximately $\mathrm{mm}$. Prior to forming the metal contacts, the peptide films are deposited on $1.5 \times 2 \mathrm{~cm}^{2}$ precleaned glass substrates. The metal contacts are formed by securing the shadow masks on top of the samples. Then gold films are deposited in a thermal evaporator system on the areas of the samples that are not protected by the shadow masks. The gold evaporation is performed at a pressure of $5 \times 10^{-6}$ Torr. The evaporation rate is $1-2 \AA / s$, and the final gold thickness is $\sim 50 \mathrm{~nm}$. Electrical measurements were performed using a Keithley parameter analyzer with a microprobe station. Tungsten needles attached to microcontrollers were placed on the large contact pads. The sum of the contact resistance that is the resistance between the tungsten probes and the Au pads and the resistance of the gold extensions are negligibly small $(<100 \Omega)$ compared to the lowest resistance values expected from the films $(\sim \mathrm{M} \Omega)$.

\section{ASSOCIATED CONTENT}

\section{(5 Supporting Information}

The Supporting Information is available free of charge on the ACS Publications website at DOI: 10.1021/acsnano.7b02025.

Experimental details and supplementary figures and methods (PDF)

\section{AUTHOR INFORMATION}

\section{Corresponding Author}

*E-mail: mguler@uchicago.edu.

ORCID $\odot$

Mustafa O. Guler: 0000-0003-1168-202X

Notes

The authors declare no competing financial interest.

\section{ACKNOWLEDGMENTS}

This work is partially supported by Marie Curie IRG, TUBITAK, and TUBA.

\section{REFERENCES}

(1) Hoeben, F. J. M.; Jonkheijm, P.; Meijer, E. W.; Schenning, A. P. H. J. About Supramolecular Assemblies of Pi-Conjugated Systems. Chem. Rev. 2005, 105, 1491-1546.

(2) Tovar, J. D. Supramolecular Construction of Optoelectronic Biomaterials. Acc. Chem. Res. 2013, 46, 1527-1537.

(3) Hasegawa, M.; Iyoda, M. Conducting Supramolecular Nanofibers and Nanorods. Chem. Soc. Rev. 2010, 39, 2420-2427.

(4) Channon, K. J.; Devlin, G. L.; MacPhee, C. E. Efficient Energy Transfer within Self-Assembling Peptide Fibers: A Route to LightHarvesting Nanomaterials. J. Am. Chem. Soc. 2009, 131, 12520-12521.

(5) Moulin, E.; Cid, J. J.; Giuseppone, N. Advances in Supramolecular Electronics - From Randomly Self-Assembled Nanostructures to Addressable Self-Organized Interconnects. Adv. Mater. 2013, $25,477-487$.

(6) Ardona, H. A.; Tovar, J. D. Peptide Pi-Electron Conjugates: Organic Electronics for Biology. Bioconjugate Chem. 2015, 26, 22902302.

(7) Eakins, G. L.; Pandey, R.; Wojciechowski, J. P.; Zheng, H. Y.; Webb, J. E. A.; Valery, C.; Thordarson, P.; Plank, N. O. V.; Gerrard, J. A.; Hodgkiss, J. M. Functional Organic Semiconductors Assembled via Natural Aggregating Peptides. Adv. Funct. Mater. 2015, 25, 56405649.

(8) Shao, H.; Nguyen, T.; Romano, N. C.; Modarelli, D. A.; Parquette, J. R. Self-Assembly of 1-D n-type Nanostructures Based on Naphthalene Diimide-Appended Dipeptides. J. Am. Chem. Soc. 2009, 131, 16374-16376.

(9) Amit, M.; Cheng, G.; Hamley, I. W.; Ashkenasy, N. Conductance of Amyloid Beta Based Peptide Filaments: Structure-Function Relations. Soft Matter 2012, 8, 8690-8696.

(10) Che, Y. K.; Datar, A.; Balakrishnan, K.; Zang, L. Ultralong Nanobelts Self-Assembled From an Asymmetric Perylene Tetracarboxylic Diimide. J. Am. Chem. Soc. 2007, 129, 7234-7235.

(11) Nalluri, S. K.; Shivarova, N.; Kanibolotsky, A. L.; Zelzer, M.; Gupta, S.; Frederix, P. W.; Skabara, P. J.; Gleskova, H.; Ulijn, R. V. Conducting Nanofibers and Organogels Derived From the SelfAssembly of Tetrathiafulvalene-Appended Dipeptides. Langmuir 2014, 30, 12429-12437.

(12) Lopez-Andarias, J.; Rodriguez, M. J.; Atienza, C.; Lopez, J. L.; Mikie, T.; Casado, S.; Seki, S.; Carrascosa, J. L.; Martin, N. Highly Ordered $n / p$ Co-Assembled Materials with Remarkable Charge Mobilities. J. Am. Chem. Soc. 2015, 137, 893-897.

(13) Kitamura, T.; Nakaso, S.; Mizoshita, N.; Tochigi, Y.; Shimomura, T.; Moriyama, M.; Ito, K.; Kato, T. Electroactive Supramolecular Self-Assembled Fibers Comprised of Doped Tetrathiafulvalene-Based Gelators. J. Am. Chem. Soc. 2005, 127, 1476914775 .

(14) Nalluri, S. K. M.; Berdugo, C.; Javid, N.; Frederix, P. W. J. M.; Ulijn, R. V. Biocatalytic Self-Assembly of Supramolecular ChargeTransfer Nanostructures Based on n-Type Semiconductor-Appended Peptides. Angew. Chem., Int. Ed. 2014, 53, 5882-5887.

(15) Wang, C.; Guo, Y. S.; Wang, Y. P.; Xu, H. P.; Wang, R. J.; Zhang, X. Supramolecular Amphiphiles Based on a Water-Soluble Charge-Transfer Complex: Fabrication of Ultralong Nanofibers with Tunable Straightness. Angew. Chem., Int. Ed. 2009, 48, 8962-8965.

(16) Khalily, M. A.; Goktas, M.; Guler, M. O. Tuning Viscoelastic Properties of Supramolecular Peptide Gels via Dynamic Covalent Crosslinking. Org. Biomol. Chem. 2015, 13, 1983-1987.

(17) Choi, I.; Park, I. S.; Ryu, J. H.; Lee, M. Control of Peptide Assembly Through Directional Interactions. Chem. Commun. 2012, 48, 8481-8483.

(18) Garifullin, R; Guler, M. O. Supramolecular Chirality in SelfAssembled Peptide Amphiphile Nanostructures. Chem. Commun. 2015, 51, 12470-12473. 
(19) Hong, Y. N.; Lam, J. W. Y.; Tang, B. Z. Aggregation-Induced Emission. Chem. Soc. Rev. 2011, 40, 5361-5388.

(20) Demirel, G. B.; Daglar, B.; Bayindir, M. Extremely Fast and Highly Selective Detection of Nitroaromatic Explosive Vapours Using Fluorescent Polymer Thin Films. Chem. Commun. 2013, 49, 61406142 .

(21) Khalily, M. A.; Gulseren, G.; Tekinay, A. B.; Guler, M. O. Biocompatible Supramolecular Catalytic One-Dimensional Nanofibers for Efficient Labeling of Live Cells. Bioconjugate Chem. 2015, 26, 2371-2375.

(22) Al Kobaisi, M.; Bhosale, S. V.; Latham, K.; Raynor, A. M.; Bhosale, S. V. Functional Naphthalene Diimides: Synthesis, Properties, and Applications. Chem. Rev. 2016, 116, 11685-11796.

(23) Kumar, N. S. S.; Gujrati, M. D.; Wilson, J. N. Evidence of Preferential Pi-Stacking: A Study of Intermolecular and Intramolecular Charge Transfer Complexes. Chem. Commun. 2010, 46, 5464-5466.

(24) Shao, H.; Seifert, J.; Romano, N. C.; Gao, M.; Helmus, J. J.; Jaroniec, C. P.; Modarelli, D. A.; Parquette, J. R. Amphiphilic SelfAssembly of an n-Type Nanotube. Angew. Chem., Int. Ed. 2010, 49, 7688-7691.

(25) Behanna, H. A.; Donners, J. J. J. M.; Gordon, A. C.; Stupp, S. I. Coassembly of Amphiphiles with Opposite Peptide Polarities into Nanofibers. J. Am. Chem. Soc. 2005, 127, 1193-1200.

(26) Garifullin, R.; Erkal, T. S.; Tekin, S.; Ortac, B.; Gurek, A. G.; Ahsen, V.; Yaglioglu, H. G.; Elmali, A.; Guler, M. O. Encapsulation of a Zinc Phthalocyanine Derivative in Self-Assembled Peptide Nanofibers. J. Mater. Chem. 2012, 22, 2553-2559.

(27) Nowak-Krol, A.; Fimmel, B.; Son, M.; Kim, D.; Wurthner, F. Photoinduced Electron Transfer (PET) versus Excimer Formation in Supramolecular $p / n$ heterojunctions of Perylene Bisimide Dyes and Implications for Organic Photovoltaics. Faraday Discuss. 2015, 185, 507-527.

(28) Stevens, J. S.; de Luca, A. C.; Pelendritis, M.; Terenghi, G.; Downes, S.; Schroeder, S. L. M. Quantitative Analysis of Complex Amino Acids and RGD Peptides by X-Ray Photoelectron Spectroscopy (XPS). Surf. Interface Anal. 2013, 45, 1238-1246.

(29) Roux, S.; Zekri, E.; Rousseau, B.; Paternostre, M.; Cintrat, J. C.; Fay, N. Elimination and Exchange of Trifluoroacetate Counter-Ion From Cationic Peptides: A Critical Evaluation of Different Approaches. J. Pept. Sci. 2008, 14, 354-359.

(30) Das, A.; Ghosh, S. Supramolecular Assemblies by ChargeTransfer Interactions Between Donor and Acceptor Chromophores. Angew. Chem., Int. Ed. 2014, 53, 2038-2054.

(31) Kumar, M.; Rao, K. V.; George, S. J. Supramolecular Charge Transfer Nanostructures. Phys. Chem. Chem. Phys. 2014, 16, 13001313.

(32) Renny, J. S.; Tomasevich, L. L.; Tallmadge, E. H.; Collum, D. B. Method of Continuous Variations: Applications of Job Plots to the Study of Molecular Associations in Organometallic Chemistry. Angew. Chem., Int. Ed. 2013, 52, 11998-12013.

(33) Draper, E. R.; Lee, J. R.; Wallace, M.; Jackel, F.; Cowan, A. J.; Adams, D. J. Self-Sorted Photoconductive Xerogels. Chem. Sci. 2016, 7, 6499-6505.

(34) Schroder, D. K.: Semiconductor Material and Device Characterization, 3rd ed.; John Wiley \& Sons, Inc.: Hoboken, N.J., 2006; pp $157-160$. 